\title{
ENHANCEMENT OF THE BIOPRODUCTION POTENTIAL OF AN AMYLACEOUS EFFLUENT
}

\author{
M. A. Murado, ${ }^{*} M^{a}$ P. Gonzalez, L. Pastrana, M a I. G. Siso, J. Miron \& Mª I. \\ Montemayor \\ Instituto de Investigacions Mariñas (CSIC), r/Eduardo Cabello, No. 6, Vigo-36208, \\ Spain
}

*To whom correspondence should be addressed.

\begin{abstract}
The treatment of starchy effluents could provide the basis for a series of simultaneous or alternative bioproductions easily integrable into a system of greater economic attraction that the simple production of SCP. In order to define some of the possible options, this study uses an amylaceous effluent for simultaneous production of SCP and an amylolytic preparation which is partially consumed in the saccharification of a parallel flow of the same effluent concentrated by ultrafiltration with cutoff at $100 \mathrm{kD}$.
\end{abstract}

With regard to the development of the above system, this paper describes the problems associated with ultrafiltration, the conditions that optimize saccharification of the concentrate and the requirements of various possible bioproductions that could be obtained from the saccharified concentrate.

Key words: Mussel-processing wastes, ultrafiltration, saccharification, gibberellic acid, glucose oxidase, ethanol production.

\section{INTRODUCTION}

One common way for valuation of amylaceous products is to convert them to fructose, which has a higher sweetening capacity and a better price, by means of a saccharification-isomerization process. Chemical hydrolysis is no longer used, and saccharification is now done with immobilized a-amylase and glucoamylase. The glucose is then converted to fructose using glucose isomerase, also immobilized. Although the immobilization of these enzymes is being intensively investigated (e.g. 
Vallat, 1983; Krakoviak et al., 1984; Ohtsuka et al., 1984; Kennedy et al., 1985; Szajani et al., 1985; Slininger et al., 1988), the scale-up of these processes is not economical except when used to obtain relatively high priced products. It is not there-fore worthwhile to extend them to impure substrates or those in low concentrations. In such cases, frequently associated with the depuration of waste materials, the commonest option is SCP production.

The depuration of starchy effluents with SCP production yields postincubated media whose residual amylolytic activity could sometimes allow the initiation of other valuable pathways (e.g. Saha \& Ueda, 1983), easily integrable with the rest of the system. The nature, concentration and stability of the enzymes involved are factors which, together with the characteristics of the effluent treated (origin, overall composition, polysaccharide concentration), determine which of various possible strategies might be pursued.

These strategies, which could be developed as simultaneous or alternative ways, cover from recovery and purification of the enzymes to the direct use of postincubates as amylolytic preparations for the saccharification (and subsequent increase in their versatility as microbial substrates) of parallel effluent flows, concentrated to levels adequate for the process being developed. Alcoholic fermentation, as well as the production of citric acid, gibberellins, gluconic acid and glucose oxidase are some of the possibilities in this context.

In an effort to add economic incentives to the depuration of the effluents resulting from the industrial processing of mussels (hereafter MPW), the basis of which has been described in earlier works (Murado et al., 1986, 1989, 1992; Miron et al., 1988; Siso et al., 1988; Gonzalez et al., 1992), this paper explores: the viability of the concentration of MPW by ultrafiltration; the problems of the saccharification of concentrated MPW by amylolytic preparations obtained from postincubates of Aspergillus niger and/or A. oryzae grown on the effluent; some of the possibilities and problems of the saccharified effluent as substrate for diverse bioproductions.

\section{METHODS}


General

The species used are given in Table 1. MPW, subjected to treatment according to the objective pursued in each case (see Fig. 1), was used as culture media, namely:

\section{Medium M}

MPW clarified by acidification and immediate decantation from the proteic precipitate formed (Gonzalez et al., 1992; Murado et al., 1992). The average concentration of glycogen was $10 \mathrm{~g} /$ litre. Used for the production of SCP and amylases with Aspergillus oryzae and A. niger.

\section{Media n M}

Unless another procedure is specified, this is medium $M$ concentrated by ultrafiltration at $100 \mathrm{kD}, \mathrm{n}$ being the concentration factor reached. Average level of glycogen, $10 \mathrm{n}$ g/litre.

\section{Media n M-h H}

Enzymatically hydrolysed nM medium, 10n being the concentration of total sugars in $\mathrm{g} /$ litre and $\mathrm{h}$ the degree of hydrolysis in percentage expressed as [(RS)100/TS]. Various values of $\mathrm{n}$ and $\mathrm{h}$ are used for the production of ethanol (Saccharomyces cerevisiae), gibberellic acid (Gibberella fujikuroi) and gluconic acid as well as glucose oxidase (Aspergillus niger).

Waste composition and basic microbiological methods were described in previous papers (Gonzalez et al., 1992; Murado et al., 1992). Cultures for SCP and amylase production were performed in a 3-1itre New Brunswick fermentor $\left(\mathrm{T}=30^{\circ} \mathrm{C}\right.$, aeration $=$ 1-2 litre/litre/min, agitation=200 rev/min), with $\mathrm{pH}$ controlled at 5.5. In all the other cases, $250 \mathrm{ml}$ Erlenmeyer flasks containing $50 \mathrm{ml}$ of medium at $30^{\circ} \mathrm{C}$ in a rotary shaker at $200 \mathrm{rev} / \mathrm{min}$, were used. The specific conditions of each assay will be described in connection with the corresponding results. 
Cell free media were obtained by paper filtration (Aspergilli) or centrifugation (other species). To obtain powdered amylase preparations, postincubates from A. oryzae were concentrated by ultrafiltration with cutoff at $30 \mathrm{kD}$, the retentate desalted by means a final diafiltration step, and the resulting desalted volume lyophilized (Murado et al., 1992). When stored at $4^{\circ} \mathrm{C}$, the powder retained its initial amylolytic activity for at least 30 months.

Analytical methods

Methods for determination of glycogen, total sugars, reducing sugars, glucose and oligosaccharides by HPLC, total phosphorus and nitrogen, proteins, total amylolytic activity (TAA) and specific glucoamylase activity (GA), were described or referred to in previous papers (Gonzalez et al., 1992; Murado et al., 1992). Additional analytical methods were:

Ethanol: determined by gas chromatography with FI detection (Sai Ram \& Seenayya, 1989), using a Chromosorb 103 column (80-100 mesh).

Gluconic acid: enzymatic method of Möllering \& Bergmeyer (1974).

Glucose oxidase: method of Fiedurek et al. (1986).

Gibberelic acid (GA3): determined by reverse phase liquid chromatography with spectrophotometric detection at $254 \mathrm{~nm}$, on cell free media, previously purified according to the Holbrook et al. (1961) method. A Lychrospher RP-18, $5 \mu \mathrm{m}$ column $(12.5 \times 0.4 \mathrm{~cm})$ was used at room temperature, a flow of $1 \mathrm{ml} / \mathrm{min}$ and the following elution sequence given in Table 2 .

Stastical methods

To study the combined effects of enzyme/substrate ratio, a-amylase/glucoamylase ratio, $\mathrm{pH}$ and reaction time on the saccharification of concentrated MPW (media $\mathrm{nM}$ ), a complete four variables factorial design was used (Akhnazarova \& Kafarov, 1982; Box et al., 1989). 


\section{RESULTS AND DISCUSSION}

\section{Concentration of clarified MPW}

Although the clarified effluent (medium M) is already an acceptable microbiological substrate, a previous concentration stage could be justified if the increase in its level of carbohydrates contributes to the extension of its uses. The exit temperature of the raw effluent, nearing $100^{\circ} \mathrm{C}$, no doubt reduces the energy necessary for the application of evaporating procedures and, in this way, volumes approximately equivalent to half the initial volume can be obtained. The evaporative concentration of raw MPW does nevertheless present several inconveniences. First, it is physically and economically difficult to go beyond the previously mentioned factor of 2 . Also, it causes an increase in viscosity which hinders the precipitation of proteins during the clarification process. Finally, it increases, in a non-selective manner, the concentration of all the components of the medium, and so unsuitable levels of salinity for the culture of microorganisms can be reached.

On the other hand, ultrafiltration, a technique of economic viability proved in the extensive treatment of other residual substrates (e.g. lactic whey, Lane, 1977; Hossain et al., 1983), offers, in this case, important advantages. First, applied to clarified effluents and dealing primarily with the exclusion of glycogen, with molecular weight $>100 \mathrm{kD}$ in the raw wastes, it becomes a quick and efficient process. Also, it not only solves the problem of excess salinity, but allows the production of media with deficient nutrient content of low molecular weight, which constitutes an essential aspect of the production of certain secondary metabolites (e.g. gibberelic acid).

In a typical process, the clarified effluent (medium $\mathrm{M}$ ) is concentrated until media $\mathrm{nM}$ is obtained $(\mathrm{n}=$ concentration factor) with glycogen levels ranging from 70 to $100 \mathrm{~g} /$ litre (7M-10M) with a low nitrogen content (400-900 mg/litre, proteinaceous 75-90\%). The operation is carried out in hollow fibre cartridges (100 Amicon DC 10LA) with cutoff at $100 \mathrm{kD}$. The use of two or two series of parallel cartridges allows them to be cleaned alternatively by reverse flushing, and therefore improves the efficiency of the treatment which, overall, includes: 
(a) A concentration phase, maintained until a volume of retentate equivalent to $\sim \frac{1}{5}$ of the initial volume is obtained. The glycogen level thus reaches $40-60$ $\mathrm{g} /$ litre, slightly increasing the concentration of peptide materials while the concentrations of the low molecular weight nutrients remain constant.

(b) A diafiltration phase, in which the draining of the permeate is compensated by the continuous addition of tap water. The polysaccharide concentration is thus maintained and that of the low molecular weight components decreased as desired.

(c) A final phase of concentration to reach the desired final level of glycogen. The set of permeates, which is discarded, represents $11 \%$ of the initial COD of the effluent.

Figure 2 is an example of this type of process, carried out with a single cartridge, without interruption or intermediate cleaning, and starting with a volume of 100 litres.

Saccharification of concentrated MPW

Direct utilization of amylolytic postincubates

Although the concentration process described in the previous section increases the strength of the medium, the fact that the source of carbon is a high molecular weight polysaccharide constitutes a restrictive factor in its versatility. This suggests the convenience of submitting it to a partial or total saccharification process.

To this effect it had been established in previous papers (Murado et al., 1989, 1992; Gonzalez et al., 1992) that the postincubate media from cultures of diverse amylolytic species (suitable for the production of SCP) on medium M, contained an appreciable level of amylases. Therefore, a preliminary assay was carried out in which various aliquots of a medium $2 \mathrm{M}$ were treated with equal volumes of postincubates of Aspergillus niger (glucoamylase predominant) and A. oryzae ( $\alpha$-amylase predominant), used alone or combined in different proportions. 
Having quantified the degrees of hydrolysis obtained in terms of reducing sugars and glucose (Fig. 3), it was observed that, when used alone at equal volumes, the postincubates of A. oryzae (with a greatly superior TAA) produce better results than those of A. niger. Nevertheless, when mixtures of postincubates were used, the contribution of A. niger had a clearly favourable effect, particularly when hydrolysis was measured in terms of glucose, suggesting the enrichment of the mixture in glucoamylase as a specific causal factor.

It can be concluded that the use of this type of mixture, equivalent to a postincubate of A. oryzae enriched with glucoamylase, would optimize the efficiency of the process in terms of ratio TAA/percentage of hydrolysis. But at the same time, this involves a dilution of the TAA from A. oryzae with the postincubate from A. niger. Since in our conditions the cost of obtaining both postincubates is the same, and since in any case those from A. oryzae are capable of achieving complete hydrolysis, it seems reasonable to overlook the maximum efficiency of the process in favour of the real cost. We therefore suggest that postincubates from A. oryzae be employed.

The possibility of making the hydrolysis process continuous in a piston-flow reactor was then assayed by introducing, by means of a peristaltic pump, equivalent flows of a postincubate from A. oryzae $(\mathrm{TAA}=30 \mathrm{EU} / \mathrm{ml})$ and a medium $2 \mathrm{M}($ glycogen $=20$ $\mathrm{g} /$ litre), in a column of $21 \times 1.74 \mathrm{~cm}$. The results obtained at different temperatures and outflows are shown in Fig. 4, where it can be observed how a degree of hydrolysis of $96 \%$ is reached at $55^{\circ} \mathrm{C}$, with a residence time of $13 \mathrm{~h}$. The reversal of the general trend of the percentage of hydrolysis to increase at lower flow-rates, detected at $60^{\circ} \mathrm{C}$, indicated that the thermal tolerance of the enzymatic system had been reached.

It is interesting to note that the degree of hydrolysis reached proves that the operation of the reactor really takes place in piston-flow regime. Since such a regime cannot be reproduced by adding tracers ( $\mathrm{HCI}, \mathrm{NaOH}$, methylene blue) to the MPW flow in the absence of enzyme, it is reasonable to suppose that it is favoured by the decreasing viscosity gradient (Miranda et al., 1991) which is produced in the column as a result of the progressive hydrolysis of glycogen. 
Figure 5 shows hydrolysis of media concentrated up to $40 \mathrm{~g} /$ litre of glycogen with postincubates of A. oryzae $(\mathrm{TAA}=35 \mathrm{EU} / \mathrm{ml})$ in an agitated tank, at two temperatures and different volumetric proportions. The difference is slight but the process is better when carried out at $50^{\circ} \mathrm{C}$, particularly at the lowest proportions of enzyme/substrate (postincubate/medium), and the degree of hydrolysis stabilizes at values of $\sim 95 \%$ after a $40-\mathrm{h}$ incubation period.

There are, nevertheless, clear limitations to the direct use of the postincubates. Assuming an initial TAA $(\mathrm{EU} / \mathrm{ml}) /$ glycogen $(\mathrm{mg} / \mathrm{ml})$ ratio of about 0.44 (see Fig. 5) in the incubation mixture, the initial glycogen/final glucose relations are of the order shown in Fig. 6, from which it appears that there is little point in achieving high glycogen concentrations for subsequent dilution with increasing proportions of postincubates.

Hydrolysis with amylase preparations from A. oryzae on medium M

The dilution of the hydrolysate can of course be compensated by the concentration of the postincubates, or, at the limit, with the use of powdered enzymatic preparations. In order to study this possibility the preparations obtained as described in a previous paper (Murado et al., 1992), from postincubates of A. oryzae on medium M (TAA $=60.85$ $\mathrm{EU} / \mathrm{mg}, \mathrm{GA}=0.43 \mathrm{EU} / \mathrm{mg})$, were assayed.

It should be pointed out that the joint action of $\alpha$-amylase and glucoamylase on polysaccharide is a complex process, which, according to the relative proportions of the enzymes and the molecular weight of the substrate, can have positive synergic effects (Fujii \& Kawamura, 1985; Fujii et al., 1988) and, probably, negative ones also (Miranda et al., 1987), as a consequence of the different rates at which $\alpha$-amylase creates, or fails to create, substrates of an optimum molecular size for the glucoamylase. In these circumstances, and given the characteristics of the preparation used, the process of enzymatic hydrolysis was studied by means of a complete first-order factorial plan (Akhnazarova \& Kafarov, 1982; Box et al., 1989), considering the following four variables (range and coding in Table 3 ). 
(1) Initial concentration of glycogen in the incubation mixture. The levels of this variable, which can also be interpreted as the proportion enzyme/substrate, were obtained by adding the enzymatic solutions used to $\mathrm{nM}$ media (always in the proportion $0.025: 1 \mathrm{v} / \mathrm{v}$ ) with 50,100 and $150 \mathrm{~g} /$ litre of glycogen.

(2) Proportion of glucoamylase/total amylolytic activity. The practical realization of this variable, which can also be interpreted as the level of glucoamylase over a constant level of $\alpha$-amylase, was achieved in the following way: a base solution of the preparation of $\mathrm{A}$. oryzae $(\mathrm{TAA}=1600 \mathrm{EU} / \mathrm{ml} ; \mathrm{GA}=11.31 \mathrm{EU} / \mathrm{ml})$ was supplemented with one and two unit increments of $11.31 \mathrm{EU} / \mathrm{ml}$ glucoamylase (NOVO AMG 300L, from A. niger). In this way the addition of these solutions to $\mathrm{nM}$ media in the proportions indicated $(0.025: 1 \mathrm{v} / \mathrm{v})$ provided incubation mixtures with levels of 0.28 , 0.56 and $0.84 \mathrm{EU} / \mathrm{ml}$ glucoamylase. It should be noted that with the poorest enzymatic solution the proportion of TAA $(\mathrm{EU} / \mathrm{ml}) / \mathrm{glycogen}(\mathrm{mg} / \mathrm{ml})$ varied between 0.27 and 0.80 according to the level of glycogen. Also that although the level of a-amylase was equal in all cases, the same thing did not happen with regard to the TAA, as a result of the interaction between the two enzymes present.

The last two variables were: (3) system $\mathrm{pH}$ and (4) hydrolysis time. In all cases the temperature was $50^{\circ} \mathrm{C}$ with slight rotary shaking $(100 \mathrm{rev} / \mathrm{min})$.

Time was included because it was suspected that some of the potential interactions of the remaining variables could exert different effects at different stages of the process. Nevertheless, it should be noted that the inclusion of time in a first-order plan is of no use without severe restrictions, the first concerning the interval of values of the variable. In this respect, and in order to operate in conditions of minimum deviation from linearity, the time range was determined according to the results of a previous assay, with the remaining variables in the centre of the experimental domain (Fig. 7), and it was found that the period of 5-25 h reasonably fulfilled that condition.

The results obtained provided the following empirical equation (where $\mathrm{H}$ is the percentage of hydrolysis for the period 5-25 h) for the description of the system: $\mathrm{H}=68.43+5.78 \mathrm{GA}-12.94 \mathrm{~S}-2-25 \mathrm{pH}+14.30 \mathrm{t}$ $+2.30 \mathrm{pHt}+2.34 \mathrm{GASt}-2.30 \mathrm{SpHt}$ 
Table 4 shows the experimental matrix, as well as the results observed and expected, the significance of the coefficients and the analysis of the global validity of the model (in all cases $\alpha=0.05$ ), and Fig. 8 represents some of the more illustrative response surfaces. The set of results indicates that the system (with a little convexity $\left[\mathrm{H}_{\mathrm{o}}>\mathrm{H}\right]$ in the response surface that suggests a slight second-order component) can be satisfactorily described by first-order with the equation proposed, as is proved by the relation between total and experimental error, as well as that existing between lack of fitting and experimental error.

Among the more notable characteristics of the system studied from a practical point of view, it should be first indicated that the experimental range includes conditions that allow an exhaustive hydrolysis of the substrate, even at concentrations above 100 $\mathrm{g} /$ litre, including an important effect of the glucoamylase even at the low levels considered. This means that the exclusive use of preparations of A. oryzae is viable, since, although the experimental plan was carried out with ad-hoc mixtures of aamylase and glucoamylase, the former preparations can easily reach levels of glucoamylase similar to the experimented maximum (Murado et al., 1992), falling to lower proportions only when the corresponding cultures suffer oxygen deficiency during the phase of maximum growth-rate.

It should also be noted that although the increase in glucoamylase always contributes to the increase in response, the effect is much more noticeable at short periods and low $\mathrm{pH}$. Finally, increase of $\mathrm{pH}$ (a factor that limits the activity of the glucoamylase) requires decrease in the concentration of the substrate to maintain responses reasonably high, but this effect is appreciable mainly at short periods, while at long periods and low levels of glucoamylase it seems more convenient to favour the a-amylase by increasing the $\mathrm{pH}$.

When used to obtain media with hydrolyses ranging from 25 to 100, the proposed equation provides consistent results within the specified experimental surface. Figure 9 shows the kinetic characteristics of two operational alternatives representing processes in which the priority is either the economy of the enzymatic preparation or hydrolysis time. It indicates a high degree of adjustment with regard to the expected values and the absence, in all cases, of dextrins of polymerization degree greater than maltotriose. 
Utilization of saccharified media

The suitability of the nM-hH media as substrates for bioproductions other than SCP was verified by the three series of essays specified below, in cultures carried out in the general conditions described for operation in an Erlenmeyer flask.

Ethanol production

The assay was carried out with Saccharomyces cerevisiae reducing sugars of 30, 60, 80 and $100 \mathrm{~g} /$ litre, in Erlenmeyer flasks with airtight seals, adjusting the initial $\mathrm{pH}$ to 5.5 with $\mathrm{NaOH}$. Based on previous results (concerning the production of SCP with Endomyces fibuliger in effluents concentrated by evaporation (Murado et al., 1986) and in an experimental way, supplements of $\mathrm{NH}_{4} \mathrm{CI}$ and $\mathrm{KH}_{2} \mathrm{PO}_{4}$ were used in order to achieve initial concentrations of $\mathrm{N}$ and $\mathrm{P}$ according to the following criteria:

$\mathrm{N}=0.15+0.04 \mathrm{RS}$

$\mathrm{P}=0.03+0.01 \mathrm{RS}$

$\mathrm{N}, \mathrm{P}$ and RS being the concentrations of nitrogen, phosphorus and reducing sugars, respectively, in $\mathrm{g} /$ litre.

Figure 10 proves the medium to be, in principle, particularly suitable for the objective proposed. Biomass production was very low in all cases, and the relation ethanol production (g/litre) consumption of reducing sugars (g/litre), at values of $0.40-0.48$ over the period studied, was found to be near to maximum stoichiometric possibilities. The stabilization of the ethanol concentrations was only achieved, in a manner parallel to the exhaustion of carbohydrates, in cultures with the lowest level of reducing sugars (medium 3M-100 H). In the richest media, with remaining substrate levels between 13 and $25 \%$ of initial levels, no decrease in the rate of alcohol production could be shown. In every case the consumption of nitrogen and phosphorus (not represented) indicated that the criteria for supplementation used were clearly excessive.

Production of gibberellic acid (GA 3) 
For this objective Gibberella fujikuroi was used in media with $70 \mathrm{~g} /$ litre of total sugars (degree of hydrolysis of 50 and 100\%) and $100 \mathrm{~g} /$ litre (degree of hydrolysis 100\%). There was no difficulty in obtaining proportions of $\mathrm{C} / \mathrm{N}=40-64$, critical for the production of the hormone (Borrow et al., 1961; Bu'Lock et al., 1984), if the level of $\mathrm{N}$ is controlled during the dialysis phase, according to the procedure described in the methods section. The medium was supplemented with $\mathrm{KH}_{2} \mathrm{PO}_{4}$ until the proportion of $\mathrm{C} / \mathrm{P} \approx 40$ was obtained and its initial $\mathrm{pH}$ was adjusted to 5.0 with $\mathrm{NaOH}$.

In these conditions the results obtained (Fig. 11) indicate not only an appreciable production of the hormone, but also tendencies that promote the viability of the process. In fact, levels of GA3 reached 1-26 g/litre without having exhausted the carbohydrates, and production as well as productivity in the period studied were perceptibly higher in the less concentrated media $(7 \mathrm{M}$ better than $10 \mathrm{M})$ and, within these, in the partially hydrolysed media (7M-50H better than 7M-100H).

Glucose oxidase and gluconic acid production

For this type of assay $6 \mathrm{M}-100 \mathrm{H}$ media were used with a series of supplements to obtain a composition adequate for the requirements specified by Munk et al. (1963) and Fiedurek et al. (1986). Therefore, $\mathrm{Ca}\left(\mathrm{NO}_{3}\right)_{2} \cdot 4 \mathrm{H}_{2} \mathrm{O}$ and $\mathrm{KH}_{2} \mathrm{PO}_{4}$ were added in the necessary proportions to obtain initial levels of 2.0 and $0.5 \mathrm{~g} /$ litre of nitrogen and phosphorus respectively, as well as $0.1 \mathrm{~g} /$ litre of $\mathrm{MgSO}_{4} \cdot 7 \mathrm{H}_{2} \mathrm{O}$ and $36 \mathrm{~g} /$ litre of $\mathrm{CaCO}_{3}$. The initial $\mathrm{pH}$ was adjusted to 7.0.

Results were again satisfactory (Fig. 12). The production of gluconic acid was fast, with maximum yield detected at $95.8 \%$ (stoichiometric maximum $=108.9 \%$ ) in relation to the consumption of carbohydrates. Although the maximum detected in the production of glucose oxidase happens later (and even more so the highest relation between extra and intracellular levels of the enzyme), the decrease in gluconic acid concentrations was slow, therefore, it would seem relatively easy to obtain adequate compatibility of both production objectives.

\section{ACKNOWLEDGEMENT}


To CICYT for its financial support (project AL1 789-9O).

\section{REFERENCES}

Akhnazarova, S. \& Kafarov, V. (1982). In Experiment Optimization in Chemistry and Chemical Engineering. MIR, Moscow.

Borrow, A., Jefferys, E. G., Kessell, R. H. J., Lloyd, E. C., Lloyd, P. B. \& Nixon, I. S. (1961). The metabolism of Gibberella fujikuroi in stirred culture. Can. J. Microbiol., 7, 227-76.

Box, G. E. P., Hunter, W. G. \& Hunter, J. S. (1989). In Estadistica para Investigadores. ed. Reverte, Barcelona.

Bu'Lock, J. D. (1984). Useful metabolites of Fusarium. In The Applied Mycology of Fusarium, ed. M. O. Moss \& J. E. Smith. Cambridge University Press, London, pp. 215-29.

Fiedurek, J., Rogalski, J., Ilczuk, Z. \& Leonowicz, A. (1986). Screening and mutagenesis of moulds for the improvement of glucose oxidase production. Enzyme Microb. Technol., 8, 734-6.

Fujii, M. \& Kawamura, Y. (1985). Synergistic action of aamylase and glucoamylase on hydrolysis of starch. Biotechnol. Bioengng, 27(3), 260-5.

Fujii, M., Homma, T. \& Taniguchi, M. (1988). Synergism of $\alpha$-amylase and glucoamylase on hydrolysis of native starch granules. Biotechnol. Bioengng, 32, 9105.

Gonzalez, M. P., Siso, M. I. G., Murado, M. A., Pastrana, L., Montemayor, M. I. \& Miron, J. (1992). Depuration and valuation of mussel processing wastes.

Characterization of amylolytic postincubates from different species grown on an effluent. Bioresource Technol., 42, 133-40.

Holbrook, A. A., Edge, W. J. W. \& Bailey, F. (1961). Spectrophotometric method for determination of gibberellic acid. Adv. Chem. Series, 28, 159-67.

Hossain, M., Brooks, J. D. \& Maddox, I. S. (1983). Production of citric acid from whey permeate by fermentation using Aspergillus niger. N. Z. J. Dairy Sci. Technol., 18, $161-8$.

Kennedy, J. F., Cabral, J. M. S. \& Kalogerakis, B. (1985). Comparison of action patterns of gelatin-entrapped and surface-bond glucoamylase on an $\alpha$-amylase 
degraded starch substrate: a critical revision of reversion products. Enzyme Microb. Technol., 7, 22-8.

Krakoviak, W., Jach, M., Korona, J. \& Sugier, H. (1984). Immobilization of glucoamylase on activated aluminium oxide. Starch, 36(11), 396-8.

Lane, A. G. (1977). Production of food yeast from whey ultrafiltrate by dialysis culture. J. Appl. Chem. Biotechnol., 27, 165-9.

Miranda, M., Siso, M. I. G., Gonzalez, M. P., Murado, M. A. \& Miron, J. (1987). Amylolysis in systems with a-amylase and glucoamylase. A comparative study of six procedures of evaluation. Biotechnol. Lett. (Techn.), 1(3), 195-200.

Miranda, M., Murado, M. A., Sanroman, A. \& Lema, J. M. (1991). Mass transfer control of enzymatic hydrolysis of polysaccharides by glucoamylase. Enzyme Microb. Technol., 13, 142-7.

Miron, J., Siso, M. I. G., Murado, M. A. \& Gonzalez, M. P. (1988). Microfungus-yeast mixed cultures in the degradation of amylaceous wastes. II: an experimental design for optimization of yeast production. Biotechnol. Lett. (Techn.), 2(3), 171-6.

Mö11ering, H. \& Bergmeyer, H. U. (1974). D-Gluconate. In Methods of Enzymatic Analysis, Vol. 3, ed. H. U. Bergmeyer. Academic Press, New York, pp. 1243-7. Munk, V., Pásková, J. \& Janus, J. (1963). Glucose oxidase of Aspergillus niger. I: Factors influencing glucose oxidase activity in submerged cultivation of Aspergillus niger on synthetic medium. Folia MicrobioL 8, 203-14.

Murado, M. A., Gonzalez, Mª P., Montemayor, Mª I., Reiriz, Mª J. F. \& Franco, J. M. (1986). Produccion de proteina unicelular en efluentes del procesado de mejillon. I: Utilizacion de levaduras en cultivos axonicos y mixtos. Inv. Pesquera., 50 (4), 571 605.

Murado, M. A., Siso, Mª I. G., Gonzalez, Mª P., Franco, J. M. \& Miron, J. (1989). Producci6n de proteina unicelular a partir de efluentes de la elaboracion del mejillon. II: Utilizacion de microhongos. Rev. Agroqim. Tecnol. Alim., 29(2), 20920.

Murado, M. A., Siso, M. I. G., Gonzalez, M. P., Montemayor, M. I., Pastrana, L. \& Pintado, J. (1993). Characterization of microbial biomasses and amytolytic preparations obtained from mussel processing wastes treatment. Bioresource TechnoL, 43, 117-25.

Ohtsuka, Y., Kawaguchi, H. \& Yamamoto, T. (1984). Immobilization of a-amylase on polymeric carriers having different structures. J. AppL Polym. Sci., 29, 3295-306. 
Saha, B. C. \& Ueda, S. (1983). Alcoholic fermentation of raw sweet potato by a nonconventional method using Endomycopsis fibuligera glucoamylase preparation. BiotechnoL Bioengng., 25, 1181-6.

Sai Ram, M. \& Seenayya, G. (1989). Ethanol production by Clostridium thermocellum SS8, a newly isolated thermophilic bacterium. BiotechnoL Lett., 11(8), 589-92. Siso, M I. G., Murado, M. A., Franco, J. M., Miron, J. \& Gonzalez, Ma P. (1988). Microfungus-yeast mixed cultures in the degradation of amylaceous wastes, 1 : Interactions affecting amylolytic activity. Biotechnol. Lett., 10 (6), 431-6.

Slininger, P. J., Fanta, G. F. \& Abbott, T. P. (1988). Glucoamylase immobilized on acid-hydrolyzed starch graft polyacrylonitrile. Biotechnol. Bioengng., 31, 759-69.

Szajani, B., Klamar, G. \& Ludvig, L. (1985). Preparation, characterization and laboratory-scale application of an immobilized glucoamylase. Enzyme Microb. Technol., 7, 488-92.

Vallat, I. (1983). Mise en oeuvre de la glucoamylase immobilisée sur rafles de maïs en couche fluidisée. These. Inst. Nat. Polytechnique de Toulousse. 
Table 1. Microorganisms used

\begin{tabular}{ll}
\hline Species & Source \\
\hline Aspergillus oryzae & CBS 125-59 \\
Aspergillus niger & CBS 554-65 \\
Gibberella fujikuroi & NRRL 2284 \\
Saccharomyces cerevisiae & IFI 240
\end{tabular}

CBS: Centraalbureau voor Schimmelcultures. Baarn (Netherlands).

NRRL: North Research Center, North University, Peoria, Illinois (USA).

IFI: Instituto de Fermentaciones Industriales, Madrid (Spain).

Table 2. Elution sequence for determination of gibberelic acid (GA 3)

\begin{tabular}{llll}
\hline Min & $\% \mathrm{~A}$ & $\% \mathrm{~B}$ & Time of analysis \\
\hline 5 & 80 & 20 & 5 \\
5 & 70 & 30 & 10 \\
10 & 50 & 50 & 20 \\
5 & 20 & 80 & 25 \\
5 & 80 & 20 & 30
\end{tabular}

A, glacial acetic acid at 1\%, $\mathrm{pH} 4 ; \mathrm{B}$, methanol.

Table 3. Experimental domain and codification of the variables used in the factorial design for the study of saccharification

\begin{tabular}{lllll}
\hline Coded & \multicolumn{2}{l}{ Natural values } \\
\cline { 2 - 5 } values & $\begin{array}{l}\text { Substrate } \\
(\mathrm{S}: \mathrm{g} / \text { litre })^{*}\end{array}$ & $\begin{array}{l}\text { Glucoamylase } \\
(\mathrm{GA}: \text { EU/ml })^{*}\end{array}$ & $\mathrm{pH}$ & Time \\
& 50 & 0.28 & 4.4 & 5 \\
\hline-1 & 50 & 0.56 & 5.2 & 10 \\
0 & 100 & 0.84 & 6.0 & 25 \\
+1 & 150 & 0.84
\end{tabular}

Codification: $\mathrm{V}_{\mathrm{c}}=\left(\mathrm{V}_{\mathrm{n}}-\mathrm{V}_{\mathrm{o}}\right) / \Delta \mathrm{V}_{\mathrm{n}}$; decodification: $\mathrm{V}_{\mathrm{n}}=\mathrm{V}_{\mathrm{o}}+\left(\Delta \mathrm{V}^{*}{ }_{\mathrm{n}} \mathrm{V}_{\mathrm{c}}\right)$.

$\mathrm{V}_{\mathrm{c}}$, coded value; $\mathrm{V}_{\mathrm{n}}$, natural value; $\mathrm{V}_{\mathrm{o}}$, natural value in the center of the experimental domain; $\Delta V_{n}$, increment of $V_{n}$ corresponding to one unit of $V_{n}$.

*In incubation mixture. 
Table 4. Experimental results of the study of saccharification and analysis of the significance of the proposed model. Variables according to Table 2

\begin{tabular}{|c|c|c|c|c|c|c|c|c|c|}
\hline \multirow[t]{2}{*}{ GA } & \multirow[t]{2}{*}{$\mathrm{S}$} & \multirow[t]{2}{*}{$\mathrm{pH}$} & \multirow[t]{2}{*}{$\mathrm{t}$} & \multirow[t]{2}{*}{$\mathrm{H}$} & \multirow[t]{2}{*}{$\hat{\mathrm{H}}$} & \multicolumn{2}{|c|}{$\operatorname{Var}\left(\mathrm{E}_{\mathrm{e}}\right)=1.75$} & \multicolumn{2}{|c|}{$\mathrm{t}(\alpha=0.05 ; 3 \mathrm{df})=3.18$} \\
\hline & & & & & & Coefficients & $\mathrm{t}$ & Model & \\
\hline 1 & 1 & 1 & 1 & 75.33 & 75.66 & 68.43 & 231.14 & 68.43 & \\
\hline 1 & 1 & 1 & -1 & 40.83 & 42.37 & 5.78 & 17.45 & 5.78 & GA \\
\hline 1 & 1 & -1 & 1 & 81.44 & 80.14 & -12.94 & 39.10 & -12.94 & $\mathrm{~S}$ \\
\hline 1 & 1 & -1 & -1 & 50.05 & 46.87 & -2.25 & 6.78 & -2.25 & $\mathrm{pH}$ \\
\hline 1 & -1 & 1 & 1 & 100.00 & 101.46 & 14.30 & 43.19 & 14.30 & $\mathrm{t}$ \\
\hline 1 & -1 & 1 & -1 & 66.85 & 68.34 & 1.04 & 3.15 & NS & GA.S \\
\hline 1 & -1 & -1 & 1 & 93.19 & 96.74 & -0.82 & 2.47 & NS & GA.pH \\
\hline 1 & -1 & -1 & -1 & 82.82 & 82.04 & -0.62 & 1.87 & NS & GA.t \\
\hline-1 & 1 & 1 & 1 & 58.82 & 59.42 & -0.53 & 1.59 & NS & S.pH \\
\hline-1 & 1 & 1 & -1 & 34.32 & 35.51 & 0.45 & 1.37 & NS & S.t \\
\hline-1 & 1 & -1 & 1 & 63.79 & 63.91 & 2.30 & 6.96 & 2.30 & pH.t \\
\hline-1 & 1 & -1 & -1 & 36.19 & 40.00 & -0.24 & 0.74 & NS & GA.S.pH \\
\hline-1 & -1 & 1 & 1 & 95.42 & 94.59 & 2.34 & 7.08 & 2.34 & GA. S.t \\
\hline-1 & -1 & 1 & 1 & 54.78 & 52.11 & 0.93 & 2.82 & NS & GA.pH.t \\
\hline-1 & -1 & -1 & 1 & 90.69 & 89.88 & -2.30 & 6.95 & -2.30 & S.pH.t \\
\hline
\end{tabular}




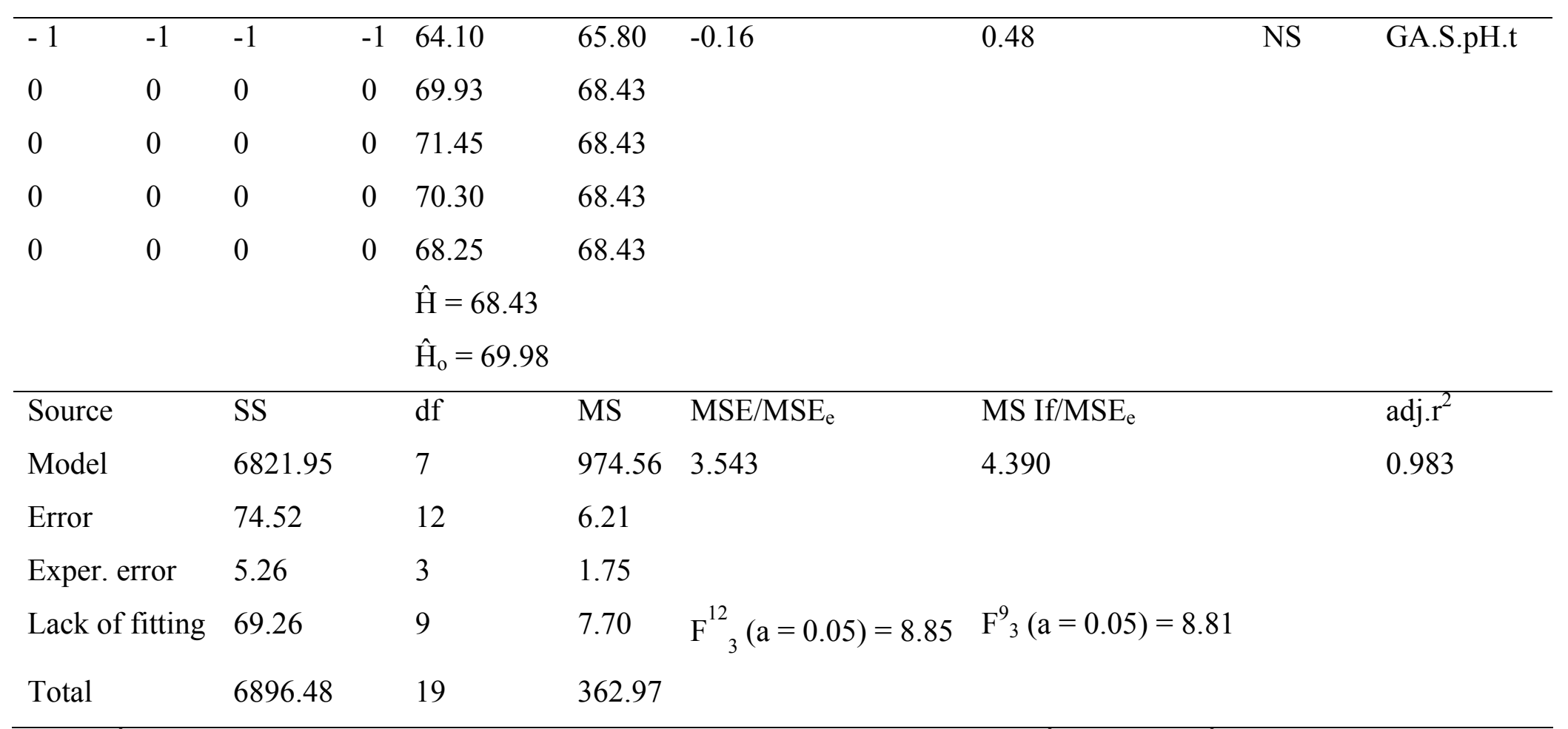

$\mathrm{H}$ and $\hat{\mathrm{H}}$, percentage of hydrolysis obtained and expected; $\mathrm{E}_{\mathrm{e}}$, experimental error; $\hat{\mathrm{H}}$, intercept; $\hat{\mathrm{H}}_{\mathrm{o}}$, experimental value in the centre of the domain. 
Fig. 1. Flow diagram of the proposed process. MPW, mussel processing wastes; A \& D, acidification of the effluent and spontaneous decantation of the proteic precipitate formed; $\mathrm{M}$, clarified wastes ( $\mathrm{M}$ medium); $\mathrm{A}_{0}$, culture of $\mathrm{A}$. oryzae; $\mathrm{SD}$, sediments (1: crude, 2: purified) obtained from Clarification of MPW; SCP, microbial biomass; PI, cell-free medium (postincubate) from A. oryzae culture; UF, ultrafiltration (cutoff 30 or 100 kD); L, lyophilization; P, permeate; PAP, powdered amylolytic preparation; nM, concentrated M medium; SC, saccharification; $\mathrm{nMH}$, concentrated and hydrolyzed $\mathrm{M}$ medium; Sc, culture of Saccharomyces cerevisiae. Production of ethanol (EtOH); Gf, culture of Gibberella fufikuroi. Production of gibberellic acid (GA3); An, culture of Aspergillus niger. Production of gluconic acid (GA) and glucose oxidase (GOD).

Fig. 2. Kinetics of MPW ultrafiltration (cutoff: $100 \mathrm{kD}$ ). Dotted lines indicate the beginning of the different phases (see text) (Vp, permeate volume; Vr, retentate volume; F, flow (from two consecutive measurements); F, flow (from zero time to actual measurement); P, total phosphorus; Nt, total nitrogen; NPr, protein nitrogen; Gg, glycogen)

Fig. 3. Percentage of glycogen hydrolysis at $40^{\circ} \mathrm{C}$ (RS as reducing sugars; $\mathrm{G}$ as glucose) by postincubates from Aspergillus niger (A1) and A. oryzae (A2), acting separately (left) and jointly (right) on concentrated MPW (20 g/litre glycogen). Postincubates (diluted with distilled water if necessary) were combined with equal volumes MPW to give incubation mixtures containing: glycogen: $10 \mathrm{~g} / \mathrm{litre}$ and TAA: $2 \mathrm{EU} / \mathrm{ml}$ in A1, 20 $\mathrm{EU} / \mathrm{ml}$ in $\mathrm{A} 2$ and $3 \mathrm{EU} / \mathrm{ml}$ in the different combinations of $\mathrm{A} 1+\mathrm{A} 2$ (the latter in volumetric ratios of $3: 2,1: 1,1: 2$ and 1:4).

Fig. 4. Continuous hydrolysis of MPW (20 g/litre glycogen) by postincubates from A. oryzae in a tubular, pistonflow reactor at four temperatures (see text). Residence time (hours) $=0.83 /$ flow $(\mathrm{ml} / \mathrm{min})$.

Fig. 5. Glycogen hydrolysis by postincubates from A. oryzae acting on concentrated MPW (40 g/litre glycogen) at two temperatures. Postincubates (P) were combined with MPW in the noted volumetric proportions. 
Fig. 6. Relations between initial glycogen in MPW and potential glucose obtained by saccharification, at $50^{\circ} \mathrm{C}$ and two TAA levels.

Fig. 7. Kinetics of glycogen hydrolysis in conditions corresponding to the centre of the experimental domain specified in Table 2. RS, reducing sugars; TS, total sugars.

Fig. 8. Response surfaces obtained in the hydrolysis of concentrated MPW, according to the experimental plan defined in Tables 2 and 3. GA, glucoamylase; S, substrate (glycogen), both in coded values.

Fig. 9. Characteristic kinetics of two extreme operational alternatives: left; $G A=1, S=$ $-1, \mathrm{pH}=-1$ : right; $\mathrm{GA}=-1, \mathrm{~S}=1, \mathrm{pH}=1$ (coded values). (TS, total sugars; $\mathrm{RS}$, reducing sugars; G, glucose; Mt, maltose; Mtt, maltotriose)

Fig. 10. Ethanol production by Saccharomyces cerevisiae in $\mathrm{nM}-100 \mathrm{H}$ media with 30 , 60, 80 and 100 g/litre glucose (B, biomass; Gc, glucose consumption; EtOH, ethanol production)..

Fig. 11. Gibberellic acid production by Gibberella fujikuroi in media with different concentrations and degrees of hydrolysis (GA3, gibberellic acid; TS, total sugars).

Fig. 12. Production of glucose oxidase and gluconic acid by Aspergillus niger in 6M$100 \mathrm{H}$ media $\left(\mathrm{GOD}_{\mathrm{i}}\right.$ and $\mathrm{GOD}_{\mathrm{e}}$, intra- and extra-cellular glucose oxidase, respectively). 